\title{
Orta Anadolu Bölgesi Kuru Koşullarında Buğday Tabanı Üretimde Doğrudan Ekim
}

\author{
İran GÜLTEKİN ${ }^{1} \quad$ Fevzi PARTIGÖÇ $^{1} \quad$ Serpil Gültekin $^{1} \quad$ Yasin KAYA $^{1}$ \\ Rifat Zafer ARISOY ${ }^{1} \quad$ Alper TANER $^{2}$ \\ ${ }^{1}$ Bahri Dağdaş Uluslararası Tarımsal Araştırma Enstitüsü, PK 125 Konya \\ ${ }^{2}$ Ondokuz Mayıs Üniversitesi Ziraat Fakültesi Tarımsal Mekanizasyon Bölümü, Samsun \\ $\square$ : irfangultekin@yahoo.com
}

Geliş (Received): 04.11.2017

Kabul (Accepted): 15.12.2017

\begin{abstract}
ÖZET: Orta Anadolu Bölgesi kuru koşullarında tarımsal üretimin çoğunluğunu geleneksel toprak işleme ile yürütülen buğday üretimi oluşturmaktadır. Buğday veriminde istikrarın sağlanması ve arttırılması için, nadas uygulaması önerilmekte ve tercihte görmektedir. Ancak nadasa bırakılan alanların yoğun işlenmesi üretim maliyetlerini artırmakta ve topraklarda olumsuz etkilere neden olmaktadır. Buna karşın dünyada doğal kaynakların korunup geliştirilmesi ve getirdiği ekonomik avantajlar nedeniyle doğrudan ekim (DE) giderek yaygınlaşmaktadır. Bölge koşullarında yürütülen farklı çalışmalara göre DE'min uygulanabilir bir yöntem olduğu belirlenmiştir. DE'de toprakların işlenmemesi, toprak yüzeyinin mümkün olduğunca bitki veya anızla kaplı tutulması yanında, ekim nöbeti de önerilmektedir. Değişik ekim nöbeti etkilerinin belirlenmesi için 2011-2014 yılları arasında Konya'da geleneksel ekim (GE) ve DE yöntemlerinde nadas, nohut, mercimek, macar fiği ve aspir sonrasında buğday verimlerine bakılmıştır. Elde edilen sonuçlara göre, buğday verimlerinin yıllara, ekim yöntemlerine ve ön bitkilere bağlı olarak değişkenlik gösterdiği tespit edilmiştir. Çalışmanın ilk yılında $219 \mathrm{~kg} / \mathrm{da}$ olarak belirlenen buğday verimi daha sonraki yıllarda sirasıyla 244 ve $237 \mathrm{~kg} / \mathrm{da}$ olarak gerçekleşmiştir. Ortalama olarak buğday verimi GE'de $226 \mathrm{~kg} / \mathrm{da}$ ve DE'de $241 \mathrm{~kg} / \mathrm{da}$ belirlenmiştir. Nadas sonrasında buğday verimleri $286 \mathrm{~kg} / \mathrm{da}$ olarak belirlenirken, mercimek, nohut, macar fiği ve aspir sonrasında sirasıyla $249,228,223$ ve $182 \mathrm{~kg} / \mathrm{da}$ olarak elde edilmiştir. Uygulama yöntemlerinin her ikisinde de en düşük verimler aspir sonrasında en yüksek verimler nadas uygulamasından alınmıştır. DE yönteminden elde edilen verimler üzerinde uygulanan yetiştirme tekniğinin etkileri gözlenmiş̧tir. Özellikle, ekim zamanının ve yabancı ot yoğunluğunun etkisi belirgin olmuştur. Sonuç olarak DE'in farklı bir üretim yöntemi olduğu ve kendi içeriğinde gerekli uygulamaların yapılması durumunda, geleneksel yöntemden daha iyi sonuçlar verdiği görülmektedir.
\end{abstract}

Anahtar Kelimeler: Kuru koşullar, buğday, toprak işleme, münavebe, doğrudan ekim,

\section{No-till Systems in Dry Contitions for Wheat-Based Production of Central Anatolian Region}

ABSTRACT: In dry conditions of Central Anatolia Region, the majority of agricultural activity is wheat production which is carried out with traditional tillage. In order to ensure and increase the stability of wheat yield, fallow application is recommended and farmers also preferred. However, intensive tillage of the follow areas increases production costs and causes negative effects on the soil. On the other hand, No-till is becoming increasingly widespread in the world, due to the conservation and development of natural resources and the economic advantages it brings. It has been determined that No-till is a feasible method according to different studies carried out in the region. In No-till, eliminating soil tillage, keeping the surface of the soil covered with plants or stubble as much as possible, crop rotation are also suggested. In order to effects of different crop seasons, wheat yields were determined in Konya between 2011 and 2014 for conventional systems (CS) and No-till methods after fallow, chickpea, lentil, hungarian vetch and safflower. According to the results obtained, wheat yields were found to vary depending on years, methods and pre-planting. Wheat yield, which was determined as $219 \mathrm{~kg} / \mathrm{da}$ in the first year of study was realized as 244 and $237 \mathrm{~kg} /$ da respectively in following years. On average wheat yields are $226 \mathrm{~kg} / \mathrm{da}$ in CS and $241 \mathrm{~kg} / \mathrm{da}$ in No-till. Wheat yields were determined as $286 \mathrm{~kg} / \mathrm{da}$ after fallow, 249, 228, 223 and $182 \mathrm{~kg} / \mathrm{da}$ respectively after lentil, chickpea, hungarian vetch and safflower. In both of the methods of application, the lowest yields were obtained after the safflower and the highest yields from the after fallow. The effects of agronomical practices on wheat yields obtained from No-till were observed. In particular, the time of sowing and the influence of weed density became evident. As a result, it is seen that No-till is a different production method and that if necessary applications are made in its own content, it gives better results than CS.

Key Worlds: Dry conditions, wheat, tillage, crop rotation, no-till,

\section{GİRIȘ}

Orta Anadolu Bölgesinin kuru koşullarında tarihsel olarak uzun bir geçmişe sahip buğday tarımı tarla bitkileri ekim alanlarının yaklaşık \% 70'ini kaplamaktadır (Anonim 2017). Üretim alanlarının tamamına yakınında ise yoğun sayılabilecek şekilde toprak işleme yapılmaktadır. Toprak işlemeye dayalı sistem de yağışın yetersiz ve dağılımındaki dengesizlikler Bölgede nadası ön plana çıkarmaktadır. Çünkü nadas döneminde yapılan toprak işlemelere bağlı olarak alınan yağışların \% 29'una kadar toprakta biriktirilebilmesinin etkisiyle nadas sonrası alınan 
buğday verimleri genellikle diğer ekim nöbetlerinden daha yüksek gerçekleşmiştir (Karaca, 1987). Bunun sonucu olarak ta bölgede yaklaşık olarak 5 milyon ha alanda tarla bitkileri üretimi yapilırken 2,5 milyon ha civarında alan bir yıl boyunca sadece toprak işleme yapılarak nadasa terk edilmektedir (Anonim 2017). Böylelikle bir sonraki yıl verimleri garanti edilmek istenmektedir. $\mathrm{Bu}$ da başta organik madde miktarında azalma olmak üzere topraklarda yapısal bozulmalara neden olmaktadır (Akkuş ve Bayat, 1993). Uygulamadaki artan yıl sayısı olumsuz etkiyi giderek daha belirgin hale getirmektedir (Ryan ve ark 2011). Ayrıca üretim maliyetlerini de yükseltmektedir (Gültekin ve ark 2011).

Benzer sorunların yaşandığı dünyanın değişik yerlerinde geçtiğimiz yüzyılda üretim miktarlarını artırma yanında üretim alanlarının korunup geliştirilmesi gerektiği ortaya çıkmıştır. Bu kapsamda farklı toprak işleme yöntemleri ve alet makine kombinasyonları üzerinde durulmuş, azaltılmış toprak işleme kavramı ortaya konmuştur. Zaman içerisinde koruyucu tarım tanımlaması yaygın şekilde kullanılır hale gelmiştir. Son zamanlarda geniş kitlelerce koruyucu tarım, iyi yönetilen doğrudan ekimle özdeşleştirilmiştir. Hasattan itibaren ekime kadar geçen dönemde herhangi bir nedenle toprak işleme yapılmadan ve ekimin ön bitkiye ait anızlarla kaplı tarlada \% 20' den daha az yüzey toprağının açılarak yapıldığ1 sistem doğrudan ekim olarak adlandırılmaktadır (Clabtree 2009). Birleşmiş Milletler Gıda ve Tarım Teşkilatı (FAO) doğrudan ekimin toprak yüzeyinde sürekli olarak bitki veya anızla kaplı tutularak ekim nöbeti içerisinde uygulanmasını koruyucu tarım olarak tanımlamaktadır (Anonim 2017).

Dünyada farklı yerlerinde DE üzerinde yapılan çok sayıda çalışma sonuçlarının incelenerek özetlendiği çalışma sonuçlarına göre: DE daha verimli ve getirisi çok daha yüksek bir sistem olarak ifade edilmektedir. Sistem toprak işlemeyi elemine etmesiyle mali olarak kazanç sağlamaktadır. Verimlerdeki artışa ise; azalan yüzey akışları ve artan infiltrasyon oranı, bitkinin kök bölgesinde çoğalan biyolojik aktivite ve azalan inorganik maddeye dönüşümüne bağlı artan organik madde miktarı etkilidir. DE'de ayrıca yağmur damlalarının yağış esnasında toprak yüzeyine verdiği zarar azalmakta, yatay ve düşey erozyona engel olunmakta, buharlaşma hızı düşmekte ve toprak yüzeyinde oluşabilecek aşırı sıcaklık değişiklikleri daha aza indirgenmektedir. DE getirdiği olumlu katkıların etkisiyle dünyanın değişik ekolojilerinde 150 milyon ha'dan daha fazla bir alanda uygulanmaktadır (Kassam ve $\operatorname{ark}$ (2012).

Bölgede yapılan araştırmaların sonuçlarına göre de DE'de elde edilen verimler geleneksel sisteme göre eşdeğer ya da daha iyi ve daha ekonomik bir üretim modeli olduğu görülmüştür (Gültekin 2012). Bölge koşullarında düşük girdili, yüksek verimli ve çevreye olumlu katkı sağlayan DE'in başarısı için iyi bir ekim makinesi yanında mutlak suretle ekim nöbetine ihtiyaç duyulmaktadır (Gültekin 2013). Yapılan bu çalışma ile de GE ve DE yönteminde farklı ekim nöbetlerinin buğday verimine etkisi incelenmiştir.

\section{MATERYAL ve YÖNTEM}

Deneme materyali olarak Karahan-99 (ekmeklik buğday), Gökçe (nohut) Sultan-1 (yeşil mercimek) ve Altınova (Macar fiği) ve Remzibey (aspir) çeşitlerinin yer aldığı çalışma Bahri Dağdaş Uluslararası Tarımsal Araştırma Enstitüsünün Konya Merkezde bulunan arazisinde kuru koşullarda gerçekleştirilmiştir. Çalışmada gerekli tarla koşullarını sağlamak için 2010 yılı Temmuz ayında hasat edilen buğday alanına yapılan parselasyona uygun şekilde 2011 yılında bir ön çalışma yürütülmüştür. Buğday verimleri ise 2012, 2013 ve 2014 yıllarında alınmıştır. Denemeler çakılı olarak her yıl ürün alınabilecek șekilde "Tesadüf Bloklarında Bölünmüş Parseller Deneme Deseni" ne göre dört tekerrürlü olarak yürütülmüştür. Çalışmada ana parsel konularını toprak işleme sistemleri oluşturmuştur. Ele alınan toprak işleme sistemleri, doğrudan ekim (DE): Toprağı herhangi amaçla önceden işlemeden, tohumu ve ekimle birlikte verilen gübreyi tohum yatağına bırakabilmek için en az düzeyde toprak yüzeyini açarak ekim yapan özel mibzer kullanarak uygulanan sistemdir. Geleneksel ekim (GE): soklu pullukla ilk sürüm yapılmış, gerekli sayıda ikincil işleme kazayağ $1+$ tırmık kombinasyonu ve ekim öncesinde yaylı tırmık kullanılmıştır. Ekimler geleneksel hububat mibzeri ile yapılmıştır. Alt parsellerde ise Nadas-Buğday, Mercimek-Buğday, Nohut-Buğday, ve Macar fiğiBuğday, Aspir-Buğday ekim nöbetleri yer almıştır. Parsel boyutları ekimde $10 \mathrm{~m}$ uzunluğunda ve $6 \mathrm{~m}$ genişliğinde $\left(=60 \mathrm{~m}^{2}\right)$ olmuştur. Parsel aralığ $4 \mathrm{~m}$ blok aralığı ise alet ekipman dönüşlerine imkan vermesi için $10 \mathrm{~m}$ olarak planlanmıştır. Buğday hasatları $8 \mathrm{~m}$ uzunluğunda $3,2 \mathrm{~m}$ genişliğinde $\left(=25,6 \mathrm{~m}^{2}\right)$ parsel biçerdöveri ile yapılmıştır. DE nadas uygulamasında ilkbaharda ilgili parsellere total herbisit uygulanmıştır. Ayrıca DE'de yer alan ekim nöbetleri için ekim öncesi otlanma tespit edilen parsellerde yine total herbisit uygulanarak yabancı ot kontrolü sağlanmıştır. Tüm deneme parselleri için buğdayda ekimle birlikte $7 \mathrm{~kg} / \mathrm{da}$ $\mathrm{P}_{2} \mathrm{O}_{5}$ ve $2,4 \mathrm{~kg} / \mathrm{da} \mathrm{N}$ verilmiştir. Erken ilkbaharda azot dozu $7 \mathrm{~kg} / \mathrm{da}$ olacak şekilde tamamlanmıştır. Ekili dönem yabancı ot kontrolleri için tüm parsellere eşdeğer dozda kimyasal uygulaması yapılmıştır. Çalışma süresince buğdayda herhangi bir hastalık veya böcek zararlısı gözlenmemiştir. Çalıșmada yer alan ön bitkiler için önerilen yetiştirme tekniği uygulamaları yapılmıştır. Tüm bitkilere ait anızlar tarlada bırakılmıştır. Yalnız tritikale ile birlikte ekilen macar fiğinde Haziran başında yeşil ot biçimleri gerçekleştirilmiştir.

Konya ilinde yıllık yağış ortalaması $318 \mathrm{~mm}$ olup alınan yağışların \% 90 buğday yetiştirme periyodu içerisinde görülmektedir. Çalışmaların yürütüldüğü yıllarda alınan yağışlar ilk iki yıl için ortalamaya yakın seyretmişken son yılda alınan yağışlar \% 30 oranında daha az gerçekleşmiştir. Alüviyal büyük toprak grubuna giren taban arazisi durumunda bulunan deneme alanı düz ve düze yakın bir topografyaya sahiptir. Yüksek kireç içeriği, orta derce alkali ve düşük oranda organik 
madde bulunduran kil bünyeli toraklarda tuz problemi yoktur.

\section{BULGULAR VE TARTISSMA}

Çalışma sonucunda elde edilen buğday verimleri yıllara göre farklılık gösterdiği için istatistiksel analizleri yıllara göre ayrı ayrı yapılmıştır. İlk çalışma yllı olan 2011-2012 üretim yllında elde edilen buğday verimleri çizelge 1' de verilmiştir.
İlk yll elde edilen verimler üzerinden yapılan varyans analizinde DK \%19,24 olarak hesaplanmıştır. Uygulama konularından ekim yöntemleri istatistiksel olarak $p<0,05$ seviyesinde önemli bulunmuştur. Buna karşı ön bitki ve uygulamaya göre ön bitki verimlerinin arasındaki farklılığın istatistiksel olarak önemsiz olduğu görülmüştür.

Çizelge 1. 2011-2012 üretim yılında Konya kuru koşullarında farklı toprak işleme ve değişik ön bitki sonrasında elde edilen buğday verimleri $(\mathrm{kg} / \mathrm{da})$

\begin{tabular}{lcccccc}
\hline Ekim Yöntemi & \multicolumn{7}{c}{ Ön bitki } \\
& Nadas & Mercimek & Nohut & Macar fiği & Aspir & Ortalama \\
\cline { 2 - 7 } Geleneksel Ekim & 260 & 271 & 200 & 250 & 190 & $\mathbf{2 3 4} \mathbf{A}$ \\
Doğrudan Ekim & 199 & 205 & 231 & 203 & 182 & $\mathbf{2 0 4} \mathbf{B}$ \\
ORTALAMA & $\mathbf{2 3 0}$ & $\mathbf{2 3 8}$ & $\mathbf{2 1 5}$ & $\mathbf{2 2 6}$ & $\mathbf{1 8 6}$ & $\mathbf{2 1 9}$ \\
\hline
\end{tabular}

Elde edilen bu sonuçlara göre GE yönteminden elde edilen $234 \mathrm{~kg} / \mathrm{da}$ buğday veriminin $\mathrm{DE}$ yönteminden alınan $204 \mathrm{~kg} / \mathrm{da}$ verimden daha iyi olduğu görülmektedir. Uzun yıllar toprak işlemeye dayalı tarım yapılan alanlarda DE'e geçişin ilk yıllarında genelde benzer sonuçlar ifade edilmektedir. Bunun DE'le birlikte değişen toprak dinamiklerinden kaynaklandığ 1 zaman içerisinde dengelerin kurularak verimde iyileşmelerin görüldüğü bilinmektedir (Sayre ve ark 2006).

İkinci çalışma y1lı olan 2012-2013 üretim sezonunda elde edilen buğday verimlerinden yapılan varyans analizinde DK \%13,94 olarak belirlenmiștir. Buğday verimlerinin istatistiksel olarak ekim yöntemleri, ön bitki ve ekim yöntemlerine göre ön bitkilerden $p<0,01$ seviyesinde etkilendiği görülmüştür. Çalışmada belirlenen $218 \mathrm{~kg} / \mathrm{da} \mathrm{DE}$ ortalama buğday veriminin 271 $\mathrm{kg} / \mathrm{da}$ GE’e göre oldukça düşük kaldığı görülmektedir.
$\mathrm{Bu}$ durum bir önceki yllda olduğu gibi DE yöntemine geçişte ilk başlarda görülebilecek bir etki olması ihtimali yanında, özellikle geç kalınan ekimlerden de kaynaklanmış olabilir. Deneme koşullarında eşitliği sağlamak adına, ekimlerin aynı tarihlerde yapılmasının da bu sonuca etkili olduğu öngörülmektedir. Şöyle ki, GE yapılacak alanların ekime hazır hale getirilmesi 12 Kasım 2012 de mümkün olabilmiştir. Bölgede ekim zamanının Ekim ayından sonraya kalmasının alınan yağışlara bağlı olarak GE verimlerini düşürdüğü bilinmektedir (Topal 1993). DE toprak yüzey sıcaklığının GE yöntemine göre daha düşük kalmaktadır (Kassam ve ark 201). Dolayısı ile daha düsük sıcaklıkta çıkışlar GE göre daha zayıf kalmış olabilir. Bunun da verimlerde olumsuz etkisinin olabileceği göz ardı edilmemelidir. Nitekim bir sonraki yıl ekimlerinde tarih birliği yerine, uygun ekim zamanlarında yürütülen çalışmalarda DE daha iyi sonuçlar vermiştir.

Çizelge 2. 2012-2013 Üretim yılında Konya kuru koşullarında farklı toprak işleme ve değişik ön bitki sonrasında elde edilen buğday verimleri $(\mathrm{kg} / \mathrm{da})$

\begin{tabular}{lcccccc}
\hline Ekim Yöntemi & \multicolumn{6}{c}{ Ön bitki } \\
& Nadas & Mercimek & Nohut & Macar fiği & Aspir & Ortalama \\
\cline { 2 - 7 } Geleneksel Ekim & 333 & 265 & 245 & 294 & 218 & $\mathbf{2 7 1 ~ A}$ \\
Doğrudan Ekim & 287 & 336 & 250 & 82 & 134 & $\mathbf{2 1 8 ~ B}$ \\
ORTALAMA & $\mathbf{3 1 0}$ & $\mathbf{3 0 0}$ & $\mathbf{2 4 8}$ & $\mathbf{1 8 8}$ & $\mathbf{1 7 6}$ & $\mathbf{2 4 4}$ \\
\hline
\end{tabular}

Ön bitkilere göre en yüksek buğday verimleri sırasıyla nadas, mercimek, nohut, Macar fiği ve aspirden alınmıştır. Nadas ve Mercimek sonrası buğday verimleri arasındaki farklılık tesadüften kaynaklanıyor olmasına karşın, diğer ön bitkiler sonrası buğday verimleri nadasa göre daha düşük seviyede gerçekleşmiştir. Bu sonuç, bölgede daha önce yapılan çalı̧̧alarla benzerlik göstermektedir. Nadas döneminde toprakta biriktirilen nem, buğdayın verimi artırmaktadır (Işık ve ark 1984).

Ekim yöntemlerine göre ön bitkiler, verimleri etkilemektedir. Tüm uygulamalar içerisinde en yüksek buğday verimi $\mathrm{DE}$ mercimek sonrasında ulaşılmıştır. GE nadas, GE macar fiği ve DE nadas verimleri farklılık gösterse de istatistiksel olarak DE mercimek ile aynı grup içerisinde yer almıştır. GE mercimek, DE nohut ve GE nohut sonrası elde edilen buğday verimleri farklılık göstermekle birlikte diğer grubu olușturmuştur. Sonrasinda GE aspir, DE aspir ve DE macar fiği sonrası elde edilen buğday verimleri istatistiksel olarak farklılık gösterir nitelikte sıralanmışlardır. Macar fiği sonrası $\mathrm{DE}$ den elde edilen verimlerin çok düşük kalmış olması dikkat çekmektedir. Buna nedeni olarak ilgili parsellerde gözlenen yoğun yabancı ot popülasyonunu gösterilebilir. Karışım halinde tritikale ile birlikte ekilen macar fiği üretiminde yabacı ot kontrolü yapılmamış ve yeşil olarak Haziran ayında biçilmiştir. Buna rağmen macar fiği ekili dönemde gözlenen duvar arpası (Hordeum marinum) yoğunluğu buğday ekili dönemde artarak buğdayı bastırır görüntüye ulaşıp verimin düşmesine neden olmuştur.

Çalışmanın 2013-2014 üretim yılında elde edilen buğday verimlerinden yapılan varyans analizinde DK 
$\% 22,17$ olarak belirlenmiştir. Buğday verimlerinin istatistiksel olarak ekim yöntemleri, ön bitki ve ekim yöntemlerine göre ön bitkilerden $p<0,01$ seviyesinde etkilendiği görülmüştür. DE ortalama $301 \mathrm{~kg} / \mathrm{da}$ buğday verimine karşılık GE verimi olan $174 \mathrm{~kg} / \mathrm{da}$ olarak gerçekleşmiştir. DE verimlerinin önceki yılların aksine daha yüksek gerçekleşmiş olmasında nadas dişında kalan ön bitkiler sonrası DE'den elde edilen yüksek buğday verimleri etkili olmuştur. $\mathrm{Bu}$ uygulamaların ekimlerinin istenilen (uygun) zamanda yapılmış olması verimlerin artışının nedeni olarak görülmektedir. Şöyle ki DE ekimlerinin akabinde alınan yağışların etkisiyle çıkışlar ve gelişmeler sonbaharda GE göre daha görüntü vermişlerdir. Bunun ilerleyen süreçte verime yansıması ortaya çıkan sonucun doğmasına katkıda bulunmuştur. GE ön bitkiler sonrasında parsellerin ekim için uygun olmaması ve ekim döneminde alınan yağışların sadece uygun tohum yatağı hazırlığına vesile olması daha düşük verimlere neden olmuştur. GE macar fiği ve nadas sonrası ekimler DE ile birlikte aynı zamanda yapılmıştır. İki uygulama arasındaki farkın biriken nemden kaynaklanıyor olması muhtemeldir. Ancak Macar fiği ile diğer ön bitkiler arasındaki farkın büyük oranda ekim zamanından kaynaklandığı sonucuna varılmıștır. Gerekçe olarak ta ekim sonrası alınan yağış verimi olumlu etkilemiştir.

Çizelge 3. 2013-2014 Üretim yılında Konya kuru koşullarında farklı toprak işleme ve değişik ön bitki sonrasında elde edilen buğday verimleri $(\mathrm{kg} / \mathrm{da})$

\begin{tabular}{lcccccc}
\hline Ekim Yöntemi & \multicolumn{6}{c}{ Ön bitki } \\
& Nadas & Mercimek & Nohut & Macar fiği & Aspir & Ortalama \\
\cline { 2 - 7 } Geleneksel Ekim & 323 & 96 & 102 & 226 & 121 & $\mathbf{1 7 4 ~ B}$ \\
Doğrudan Ekim & 314 & 326 & 337 & 283 & 245 & $\mathbf{3 0 1}$ B \\
ORTALAMA & $\mathbf{3 1 9}$ & $\mathbf{2 1 1}$ & $\mathbf{2 2 0}$ & $\mathbf{2 5 5}$ & $\mathbf{1 8 3}$ & $\mathbf{2 3 7}$ \\
\hline
\end{tabular}

Ön bitkilere göre buğday verimlerinde en yüksek verim düzeyine bölge gerçeği olarak nadas sonrasında ulaşılmıştır. Sırasıyla Macar fiği, nohut ve mercimek farklı bir grup olarak nadası takip ederken aspir sonrası buğday verimleri ise en az olarak gerçekleşmiştir. Ekim yöntemlerine göre ön bitkilerden alınan verimler sirasıyla DE nohut, mercimek, GE nadas DE nadas, Macar fiği, aspir, GE Macar fiği, aspir nohut ve mercimekten alınmıștır.

\section{SONUC}

Orta Anadolu bölgesi kuru alanlarında yoğun toprak işlemeye dayalı ve nadas uygulanarak yürütülen GE yöntemi toprakların yapısını bozması, maliyetleri artırması yanında münavebe yapmayı zorlaştıran üretim modelidir. Bölge topraklarının verimliliğinin korunması ve hatta artırılması için, DE uygulanması yararlı olacaktır. Ancak DE'den beklenilen faydaların sağlanabilmesi için, ilk yıllardaki sonuçlara bakılarak karamsarlığa kapılmadan DE devam ettirilmelidir. DE yönteminin uygulanmasında yöntemin kendine özgü kuralları içerisinde, alışılagelen GE'den daha farklı yönetilmesi konusunda hassasiyet gösterilmeli, başarılı olması için de çaba harcanmalıdır.

\section{KAYNAKLAR}

Akkuş İ, A Bayat 1993.Toprak işleme sistemlerinin organik madde içeriği bakımından incelenmesi ve Konya' nın Kadınhanı ve Ilgın ilçelerindeki uygulamaları. Proceedings. 5. Uluslararası Tarımsal Mekanizasyon ve Enerji Kongresi. 12-14 Ekim 1993. Kuşadası, Türkiye

Anonim 2017. Bitkisel istatistik verileri. https://biruni.tuik.gov.tr/bitkiselapp/bitkisel.zul (Erişim tarihi 30.05.2017)

Anonim 2107. Türkiye'de Koruyucu Tarım: Teşvik Bakımından Durum, Fırsatlar ve Stratejik Çerçeve.
Food and Agriculture Organization of the United Nations. Ankara.

Clabtree B 2009. Search for Sustainability with No-till Bill in Dryland Agriculture.

Gültekin İ, Arısoy R.Z, Taner A, Kaya Y, Patigöç F, Aksoyak Ş 2011. Comparison of different soil tillage systems, under several crop rotations in wheat production at Central Anatolian Plateau in Turkey. 5th World Congress of Conservation Agriculture Incorporating 3rd Farming Systems Design Conference Brisbane Australia 26-29 September 2011 p98-99

Gültekin İ 2012. Consultant Report on the Status of Conservation Agriculture in Turkey, 2012. FAOSEC Turkey.

Gültekin İ, Arısoy R.Z, Kaya Y, Partigöç F, Gültekin S, ve Taner T 2013. Orta Anadolu Bölgesi Kışlık Tahıl Tabanlı Tarla Bitkileri Tarımında Doğrudan Ekim. İç Anadolu Bölgesi 1. Tarım ve Gıda Kongresi, 2-4 Ekim 2013 Niğde Bildiriler Cilt-I s. 42-48.

Işık M, Önceler Z, Siirt S, Kalaycı M, ve Aydın M 1984. Ülkesel NAD Araştırma Projesi, Eskişehir Zirai Araştırma Enstitüsü. 1983-1984 Yılı Gelişme Raporu. Eskişehir.

Karaca M 1987 Kuru Alanlarda Toprak İşleme. Orta Anadolu Bölge Zirai Araştırma Enstitüsü Yayınları. Ankara.

Kassam A, Friedrich T, Derpsch R, Lahmar R, Mrabet R., Basch G, Sanchez E.J, Serraj R, 2012. Conservation agriculture in the dry Mediterranean climate. Field Crops Research 132(2012)7-12

Kaya Y, Arısoy R.Z, Taner A, Aksoyak Ş, Partigöç F, Gültekin İ 2010. Geleneksel ve Doğrudan Ekim Yöntemlerinin Nohut Buğday Ekim Nöbetinde Orta Anadolu Kuru Koşullarında Karşılaştırılması. Tarım Makinaları Bilimi Dergisi (Journal of Agricultural Machinery Science) 2010, 6 (4) 267-272 
Ryan J, Kapur S, İbrikçi H, Singh M 2011. Cultivation Intensity in Relation to Organic Matter and Related Properties in a Vertisol in Southern Turkey. Journal of Sustainable Agriculture, 35:6, 613-623.

Sayre K, Govaerts B, Martinez A, Mezzalama M, Martinez M 2006. Comparison of alternative conservation agriculture technologies for rainfed production in the highlands of Central Mexico, 28
August-3 September 2006. In: Proc. 17th ISTRO Conf., Kiel, Germany, 1012-1018.

Topal A 1993. Konya ekolojik şartlarında bazı arpa çeşitlerinde (Hordeum vulgare L.) farklı ekim zamanlarının kışa dayanıklılık, dane verimi, verim unsurları ve kalite özelliklerine etkileri üzerine bir araştırma. Doktora Tezi (Basılmamış). Selçuk Üniversitesi. Konya 